Research Article

\title{
Investigation on Durability Behaviour and Optimization of Concrete with Triple-Admixtures Subjected to Freeze-Thaw Cycles in Salt Solution
}

\author{
Xuejiao Li $\mathbb{D}^{1},{ }^{1}$ Wensheng Wang $\mathbb{D}{ }^{2}$ Zhiqing Zhu $\mathbb{D}^{2}$, and Kunkun Zheng $\mathbb{D}^{3}$ \\ ${ }^{1}$ Changchun University of Architecture and Civil Engineering, Changchun 130604, China \\ ${ }^{2}$ College of Transportation, Jilin University, Changchun 130025, China \\ ${ }^{3}$ Guangdong Aohong Technology Co.,Ltd., Zhongshan 528437, China
}

Correspondence should be addressed to Wensheng Wang; wangws@jlu.edu.cn and Zhiqing Zhu; zhuzqjlu@163.com

Received 6 January 2021; Revised 23 January 2021; Accepted 29 January 2021; Published 11 February 2021

Academic Editor: Qinglin Guo

Copyright (c) 2021 Xuejiao Li et al. This is an open access article distributed under the Creative Commons Attribution License, which permits unrestricted use, distribution, and reproduction in any medium, provided the original work is properly cited.

In the seasonal frozen area of northeast China, cement concrete is usually in a working environment of cold climate and chlorine erosion coupling effect. In general, with a reasonable addition of air entraining agent (AEA) and multimineral admixtures such as fly ash, blast furnace slag, and silica fume, the durability of cement concrete under the effects of freeze-thaw and salt solution can be significantly improved in cold regions. However, due to several more compositions of cement concrete with multiple mineral admixtures, it would take excessive trial mixtures to select the desired mixture proportion based on the conventional method. This means a great deal of costs of raw materials and laboratory experimental time. In this paper, the experimental scheme of mixture proportion for air-entrained concrete with multimineral admixtures was designed based on the orthogonal experiment design method. Based on the compressive strength, rapid chloride permeability, and weight loss and relative dynamic elastic modulus after salt freeze-thaw cycles, the influence of different mineral admixtures and their dosages on the durability of concrete subjected to freeze-thaw in salt solution was analyzed. After that, based on genetic algorithm, an optimization of mixture proportion was proposed, which only requires less trial mixes and accessible optimization process. The test results indicated the superiority of airentrained concrete with multimineral admixtures when serving in salt freeze-thaw environment. Eventually, it was also verified that the optimized concrete in this paper could achieve pleasurable durability performances under salt freeze-thaw cycles.

\section{Introduction}

With the advantages of high strength, considerable durability, and promising economy, concrete has been one of the most widely used building materials in civil engineering since the 20th century [1-6]. When optimizing mix proportion of concrete in many, if not most, engineering construction of China, the trial mix with highest strength is the chosen mix proportion [7-12]. Actually, the durability indexes of concrete deserve the same attention as the strength index, especially when the concrete is working in harsh environment [13-17]. In northeast China where the authors are located, as an example, de-icing salt has been invariably used to melt ice and snow on roads for decades [18-20]. Consequently, concrete pavements and bridges suffer from freezing and thawing environment strengthened by salt solution. A large number of cases have shown that the durability of concrete with rosy frost resistance will be greatly reduced when serving in this salt freeze-thaw condition. The presence of salt solutions eventually results in premature spalling of the concrete surface [21, 22], which gives rise to additional maintenance costs every year $[23,24]$.

The air entraining agent (AEA) is undoubtedly the most critical admixture in order to improve the frost resistance of concrete $[25,26]$. The addition of air entraining agent brings a large number of tiny, enclosed bubbles inside the concrete. The work of Wellman et al. indicated that these bubbles block the growth of the bodies of ice and the generation of hydraulic pressure as water freezes in capillary cavities, effectively improving the frost resistance of concrete [27]. 
There are quite a few influential factors impacting air entrainment, in which bubble size and bubble distribution are decisive factors [28-30]. However, it is extremely difficult to obtain the bubble size and distribution in fresh concrete for engineering builders. As a rule, measuring the total air content as a quality control measure of air entrainment is practical [30]. Subsequently, much of research has suggested that the optimal air contents are invariably below $7 \%$ when giving consideration to concrete strength, frost resistance, and workability [31]. Recently, super air meter has become a popular tool for assessing air-void system of fresh concrete. Not only does the total air-void content matter but also the distance between different air bubbles plays an important role in controlling freeze-thaw damage in concrete. Powers indicated that the reason for that is the spacing factor of air voids rather than the air content, and concrete with spacing factor less than $200 \mu \mathrm{m}$ should have a good freezing-thawing resistance [32]. Yuan et al. used CT to obtain the bubble structure distribution information and proposed the voidto-void distance as a factor to evaluate the freezing-thawing resistance with deicing salts performance of cement concrete [33].

On the other hand, environment-friendly mineral admixtures for concrete such as fly ash (FA), blast furnace slag (BFS), and silica fume (SF) are strongly recommended to improve salt freeze-thaw resistance because of their contributions to microstructure of concrete $[34,35]$. Studies on mechanism for salt freeze-thaw have suggested that the invasion of chlorides is responsible for damage from salt crystals, high degree of saturation, and additional hydraulic pressure $[36,37]$. This damage can be alleviated by rational addition of mineral admixtures, which are pozzolanic and finer than cement, filling pore structure, and interfacial transition zone of concrete. Consequently, the penetration coefficient of chloride ion would be reduced significantly [38]. Moreover, the reasonable combination of multimineral admixtures would enable concrete to show better performance than that of single mineral admixture $[39,40]$. For instance, when being used together as the composite mineral admixtures in cement paste, FA can reduce the autogenous shrinkage, while SF can increase the autogenous shrinkage, making up each other accordingly [41]. In the case of addition of SF, BFS, and FA at the same time, Sun et al. believed that SF provides main prophase strength amongst these three types of mineral admixtures due to its highly early pozzolanic reaction [42]. Then, BFS begins to develop its pozzolanic effect during transitional period. After 28 days, FA also gradually exhibits its own properties and provides its contributions to the strength of concrete. In terms of improvement of resistance to concrete deteriorating factors, Bapat emphasized that the use of mineral admixtures in concrete is the cheapest alternative [43].

In northeast China, the design strength grade of C40 is sufficient for construction concrete in many cases. By contrast, the durability of concrete served in salt-frost environment has been more emphasized heavily recently. When taking the concrete technical factors such as design requirements, construction methods, times, and strength grade into consideration, the high-performance concrete might not be suitable for adoption. Accordingly, the air-entrained concrete with multimineral admixtures would be an overwhelmingly feasible and economical choice to improve the resistance of concrete to salt frost erosion. However, when using conventional method to design the mix proportion of air-entrained concrete with multimineral admixtures, a large number of trial mixes are required to select the desired combination of materials that meets special performance, which would be costly, time-consuming, and sometimes uneconomical and wasteful $[44,45]$. From these considerations, a simple genetic algorithm was applied to optimize the mix proportion design of this multiconstituent concrete in this paper. The genetic algorithm is a global optimizing method which imitates biological evolution and has an advantage over many other methods on handling multiple objectives [46]. Actually, the fitness functions of different indices such as strength, slump, material price or else, have been adopted by researchers in order to obtain optimum mix proportions for target concrete properties through genetic algorithm [47, 48]. In this paper, aiming at improving the resistance of concrete to salt frost erosion, the mix proportion of air-entrained concrete with multimineral admixtures was designed based on genetic algorithm, in which the fitness functions of salt freeze-thaw resistance indices were adopted.

This paper discussed the mix proportion design of airentrained concrete with multimineral admixtures based on genetic algorithm. Firstly, the authors earmarked the air content of concrete as a priority parameter and divided it into three feasible levels, because the influence of air entraining agent on the frost resistance of concrete is much more significant than that of mineral admixtures according to available literature and field experience. Then, the dosages of fly ash (FA), blast furnace slag (BFS), and silica fume (SF) were earmarked as secondary parameters, and the number of trial mixes with different dosages of mineral admixtures was reduced by orthogonal design. Subsequently, the salt freezethaw resistance indices such as strength, rapid chloride permeability, weight loss, and relative dynamic module of elasticity of concrete were tested and analyzed. Finally, fitness functions for testing results were derived through regression analysis and the optimum concrete mix proportions were obtained through genetic algorithm.

\section{Materials and Methods}

2.1. Raw Materials. All materials used in this paper were obtained from a concrete construction site in Jilin Province, China. The grade P.O. 42.5 ordinary Portland cement was procured from Jilin Yatai Dinglu Cement Ltd., and the physical properties meet the requirements of Chinese specification GB 175-2007. Studies have shown that concrete mixed with fly ash (FA), blast furnace slag (BFS), silica fume (SF), or air-entrainment agent (AEA) has better salt freezethaw resistance [49-52]. In order to achieve the reasonable application of mineral admixtures and AEA in concrete to improve the salt freeze-thaw resistance, FA, BFS, SF, and AEA were introduced into cement concrete. The properties and main chemical compositions of cement, FA, BFS, and SF are shown in Table 1. 
TABLe 1: Properties and main chemical compositions of cement and mineral admixtures.

\begin{tabular}{lcccc}
\hline Properties & Cement & FA & BFS & SF \\
\hline Specific gravity & 3.12 & 2.19 & 2.83 & 2.18 \\
Surface area ratio $\left(\mathrm{m}^{2} / \mathrm{kg}\right)$ & 358 & 420 & 450 & 18500 \\
$\mathrm{SiO}_{2}(\%)$ & 20.62 & 51.27 & 32.28 & 90.21 \\
$\mathrm{CaO}(\%)$ & 65.07 & 3.21 & 40.23 & 0.23 \\
$\mathrm{Al}_{2} \mathrm{O}_{3}(\%)$ & 5.14 & 28.92 & 12.92 & 0.61 \\
$\mathrm{MgO}^{(\%)}$ & 0.87 & 1.85 & 7.40 & 0.52 \\
$\mathrm{Fe}_{2} \mathrm{O}_{3}(\%)$ & 3.96 & 7.63 & 2.25 & 0.22 \\
Loss on ignition (\%) & 1.6 & 3.41 & 1.02 & 1.9 \\
\hline
\end{tabular}

Triterpenoid saponin AEA with the type of SJ-2 was used to achieve different air contents in cement concrete. And naphthalene superplasticizer was also introduced into trial concrete mixes to keep consistent workability. Referring to the study of Rakinul Islam [53], natural sand with maximum size of $9.5 \mathrm{~mm}$ was used as coarse aggregate and well-graded river sand with fineness modulus of 2.0 was used as fine aggregate, which were obtained from Jilin Province, China. The specific gravities for natural gravel and river sand are 2.76 and 2.64, respectively. The sieving test results of coarse and fine aggregates are shown in Table 2.

2.2. Mixture Proportion and Specimen Preparation. In this paper, the reasonable dosages of AEA and multimineral admixtures were studied through the orthogonal experimental design [54-56]. Considering that the influence of AEA on the frost resistance of concrete is higher than that of multimineral admixtures [31], the AEA content was regarded as the priority parameter and divided into three feasible range levels of air content, i.e., $(2.5 \pm 0.5) \%$, $(4.5 \pm 0.5) \%$, and $(6.5 \pm 0.5) \%$. Then, the orthogonal experimental design for the dosages of multimineral admixtures at each range level of air content was carried out, which is presented in Table 3. In the orthogonal experimental design, based on the existing literature [54-57], the dosage of FA or BFS should be controlled within $30 \%$ by the total weight of cementitious materials, respectively. Meanwhile, the total dosage of FA and BFS was limited to less than $40 \%$ by the total weight of cementitious materials. By contrast, the dosage of SF was controlled not to exceed $10 \%$ due to its high activity and cost.

Table 3 provides an orthogonal experimental design with three factors at three levels, in which " $A$ " means the total dosage of FA and BFS, "B" is the dosage ratio of FA to BFS, and "C" means the dosage of SF.

According to the orthogonal design in Table 3, a total of 9 groups of concrete proportions are listed in Table 4. Cement, FA, BFS, and SF were used as the main components of binders and the total binder content in all concrete specimens was kept at $423 \mathrm{~kg} / \mathrm{m}^{3}$. A target concrete strength grade of C40 was selected for pavement concrete mixtures, and the water-to-binder ratio was also kept constant at 0.40 . After that, a concrete mixer was applied to mix all the raw materials, and naphthalene superplasticizer was carefully added to the mixture to maintain a slump range of $50-70 \mathrm{~mm}$, as shown in Figure 1(a). In accordance with the Chinese specification JTG E30-2005, three groups of air content range levels, $(2.5 \pm 0.5) \%$, $(4.5 \pm 0.5) \%$, and $(6.5 \pm 0.5) \%$, were controlled and are illustrated in Figure 1(b). Then, the concrete specimens were casted and cured in the temperature and humidity control chamber for 28 days. Three replicates for each specimen were prepared for each test.

\subsection{Test Methods}

2.3.1. Compressive Strength Test. The compressive strength at the age of 28 days was tested according to the Chinese specification GB/T 50081-2019. The specimen sizes of compressive strength test are $100 \mathrm{~mm} \times 100 \mathrm{~mm} \times 100 \mathrm{~mm}$ and the universal testing machine was performed on three replicate specimens for the mechanical tests, as shown in Figure 2. For the compressive strength test, the loading rate was set as $0.5 \mathrm{MPa} / \mathrm{s}$. During the whole process of test loading, the load and deflection of the specimens were recorded in real time. Then, the corresponding compressive strength $\left(S_{c}\right)$ could be calculated as follows:

$$
S_{c}=\frac{F_{c}}{A}
$$

in which $F_{c}$ and $F_{f}$ are the compressive and flexural failure loads, respectively, and $A$ is the area of the pressure surface of specimens; $A=100^{2} \mathrm{~mm}^{2}$ in this paper.

2.3.2. Rapid Chloride Permeability Test. The rapid chloride permeability test of cement concrete was carried out to evaluate the resistance to chloride ion penetration of concrete according to the Chinese specification GBT 500822009 (ASTM 1202). These specimens of rapid chloride permeability test were $100 \mathrm{~mm}$ in diameter and $50 \mathrm{~mm}$ in height. The side surfaces of all specimens were firstly coated with rapid setting epoxy. These specimens were placed inside an automatic vacuum water-soaking machine to saturate for 18 hours and then the rapid chloride permeability of concrete specimens was determined. The setups of surface resistivity test and rapid chloride permeability test are illustrated in Figure 3.

2.3.3. Salt Freeze-Thaw Cycle Test. For the purpose of making explicit the damage process of salt freeze-thaw, the concrete specimens with size of $40 \mathrm{~mm} \times 40 \mathrm{~mm} \times 160 \mathrm{~mm}$ were immersed in $3 \%$ concentration salt solution and exposed to freeze-thaw condition at the same time. A special freeze-thaw machine was adopted to create temperature conditions, as shown in Figure 4. The duration of one freezethaw cycle was 12 hours, in which the lowest and highest temperature were $-18^{\circ} \mathrm{C}$ and $18^{\circ} \mathrm{C}$, respectively. The freezethaw test was terminated when any specimen showed considerable surface damage or reduction in relative dynamic modulus of elasticity value of more than $80 \%$ of the initial value.

After multiple salt freeze-thaw cycles, the weight of concrete specimens and ultrasonic propagation speeds in 
TABLE 2: Sieving results of coarse and fine aggregates.

\begin{tabular}{lcccccccc}
\hline Size $(\mathrm{mm})$ & & 9.5 & 4.75 & 2.36 & 1.18 & 0.6 & 0.3 & 0.15 \\
\hline \multirow{2}{*}{ Cumulative sieve residue (\%) } & Coarse & 4 & 95 & 99 & - & - & - & - \\
& Fine & - & 3.44 & 15.25 & 27.62 & 46.70 & 77.84 & 95.65 \\
\hline
\end{tabular}

TABle 3: The orthogonal experimental design of concrete with multiadmixtures in this paper.

\begin{tabular}{lccc}
\hline Properties & Level I (L-I) & Level II (L-II) & Level III (L-III) \\
\hline "A"-dosage of FA and BFS (\%) & 10 & 25 & 40 \\
"B"-dosage ratio of FA/BFS & $1: 3$ & $2: 2$ & $3: 1$ \\
"C"-dosage of SF (\%) & 3 & 6 & 9 \\
\hline
\end{tabular}

TABLE 4: Mix proportions of concrete with multiadmixtures $\left(\mathrm{kg} / \mathrm{m}^{3}\right)$.

\begin{tabular}{|c|c|c|c|c|c|c|c|c|c|c|}
\hline $\begin{array}{l}\text { Group } \\
\text { no. }\end{array}$ & A & B & $\mathrm{C}$ & $\begin{array}{l}\text { Cement } \\
\left(\mathrm{kg} / \mathrm{m}^{3}\right)\end{array}$ & Water $\left(\mathrm{kg} / \mathrm{m}^{3}\right)$ & FA (\%) & BFS (\%) & SF (\%) & Fine aggregate $\left(\mathrm{kg} / \mathrm{m}^{3}\right)$ & Coarse aggregate $\left(\mathrm{kg} / \mathrm{m}^{3}\right)$ \\
\hline 1 & L-I & L-I & L-I & 368 & 170 & 2.50 & 7.50 & 3.00 & 584 & 1240 \\
\hline 2 & L-I & L-II & L-II & 355 & 170 & 5.00 & 5.00 & 6.00 & 584 & 1240 \\
\hline 3 & L-I & $\begin{array}{l}\text { L- } \\
\text { III }\end{array}$ & $\begin{array}{l}\text { L- } \\
\text { III }\end{array}$ & 343 & 170 & 7.50 & 2.50 & 9.00 & 584 & 1240 \\
\hline 4 & L-II & L-I & L-II & 292 & 170 & 6.25 & 18.75 & 6.00 & 584 & 1240 \\
\hline 5 & L-II & L-II & $\begin{array}{l}\text { L- } \\
\text { III }\end{array}$ & 279 & 170 & 12.50 & 12.50 & 9.00 & 584 & 1240 \\
\hline 6 & L-II & $\begin{array}{l}\text { L- } \\
\text { III }\end{array}$ & L-I & 305 & 170 & 18.75 & 6.25 & 3.00 & 584 & 1240 \\
\hline 7 & $\begin{array}{l}\text { L- } \\
\text { III }\end{array}$ & L-I & $\begin{array}{l}\text { L- } \\
\text { III }\end{array}$ & 216 & 170 & 10.00 & 30.00 & 9.00 & 584 & 1240 \\
\hline 8 & $\begin{array}{l}\text { L- } \\
\text { III }\end{array}$ & L-II & L-II & 241 & 170 & 20.00 & 20.00 & 3.00 & 584 & 1240 \\
\hline 9 & $\begin{array}{l}\text { L- } \\
\text { III }\end{array}$ & $\begin{array}{l}\text { L- } \\
\text { III }\end{array}$ & L-I & 228 & 170 & 30.00 & 10.00 & 6.00 & 584 & 1240 \\
\hline
\end{tabular}

Note: the dosages of FA, BFS, and SF are the weight ratio by the total binder.

specimens were measured, as shown in Figure 4. Then, the variations of weight loss $\left(W L_{v}\right)$ and relative dynamic elasticity modulus $\left(E M_{v}\right)$ of specimens can be calculated by using equations (2) and (3), respectively:

$$
\begin{aligned}
& W L_{v}=\frac{W_{0}-W_{v}}{W_{0}} \times 100 \%, \\
& E M_{v}=\frac{E_{v}}{E_{0}}=\frac{\left(v_{v}\right)^{2}}{\left(v_{0}\right)^{2}} \times 100 \%,
\end{aligned}
$$

where $W_{0}$ and $v_{0}$ are the initial weight of concrete specimens and ultrasonic propagation speed in specimens before exposed to salt freeze-thaw condition, respectively, and $W_{v}$ and $v_{v}$ are the weight of concrete specimens and ultrasonic propagation speed in specimens after multiple salt freezethaw cycles, respectively.

\section{Results and Discussion}

\subsection{Orthogonal Experimental Analysis}

3.1.1. Compressive Strength. The range analysis results of compressive strength of concrete with triple-admixtures are shown in Figure 5. It can be seen from Figure 5 that the factors affecting the compressive strength of concrete with triple-admixtures are as follows in the order of primary and secondary: dosage of SF > dosage ratio of FA/BFS > dosage of FA and BFS. This shows that the dosage of SF has more influence on the compressive strength of concrete than the other two factors. On the whole, the compressive strength of concrete with triple-admixtures first increases and then decreases with the increase of dosage of FA and BFS. As the dosage ratio of FA/BFS increases, the compressive strength of concrete with triple-admixtures shows a downward trend. This may be due to the fact that BFS enhances the strength of concrete better than FA. However, the compressive strength of concrete with triple-admixtures increases significantly with the dosage of SF increasing. This is because SF contains a large amount of amorphous silica, which has a strong cementing force and can react with cement in a very short time to form a high-strength substance and then improve the strength of concrete. On the other hand, although the dosage of SF has the greatest impact on the compressive strength of concrete with triple-admixtures, the other two factors still have important effects that cannot be ignored. In addition, comparing the compressive strength results of concrete with different air contents, it can be seen that the compressive strength of concrete with triple-admixtures decreases with the increase of air contents. 


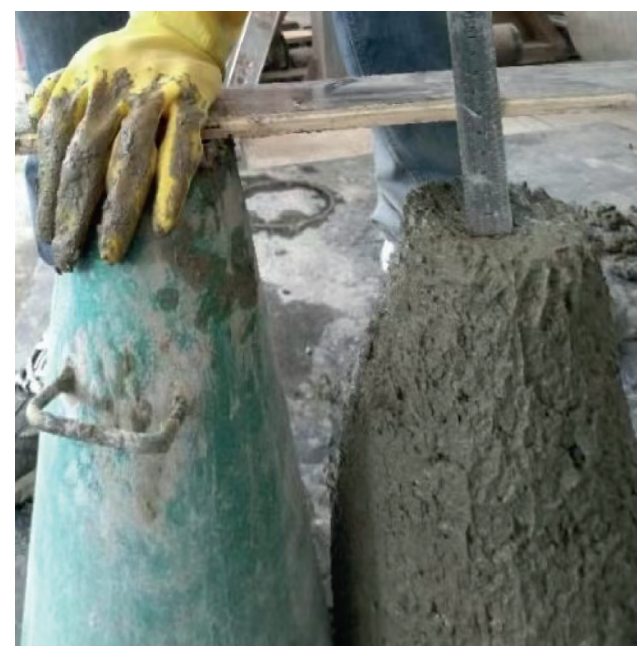

(a)

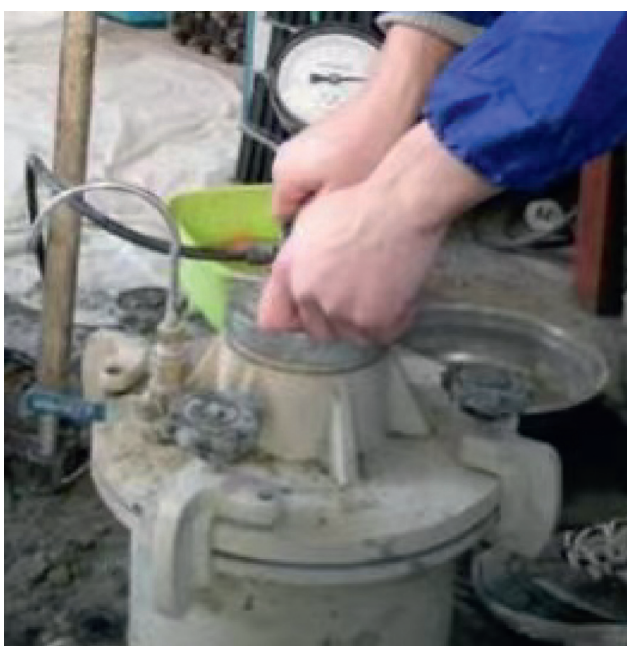

(b)

Figure 1: Parameters control of cement concrete during the specimen preparation. (a) Slump. (b) Air content.

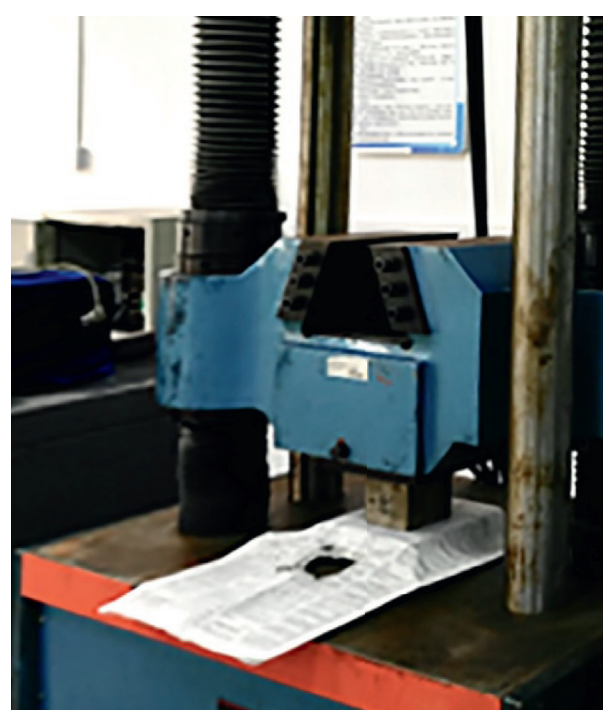

FIgURE 2: Compressive strength test of cement concrete used in this paper.
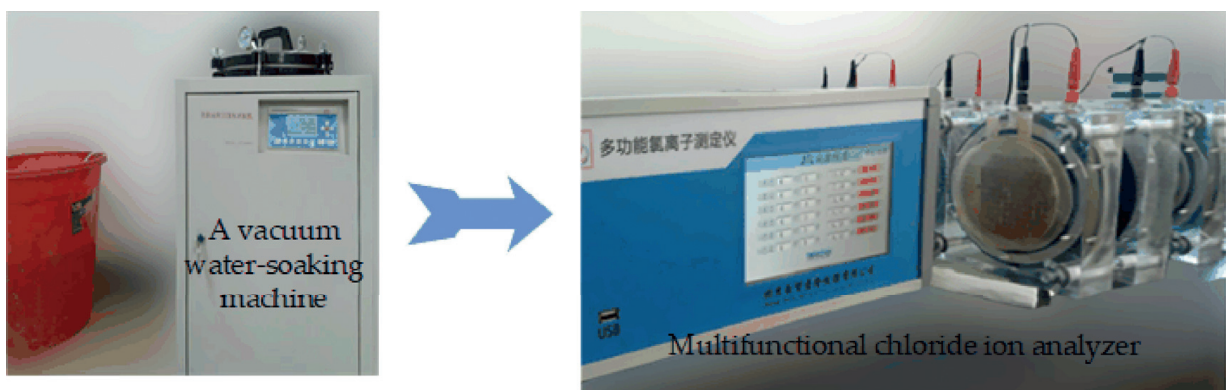

FIGURE 3: Rapid chloride permeability test of cement concrete in this paper.

3.1.2. Rapid Chloride Permeability. The range analysis results of rapid chloride permeability of concrete with tripleadmixtures are shown in Figure 6. It can be seen from Figure 6 that the factors affecting the rapid chloride permeability of concrete with triple-admixtures are as follows in the order of primary and secondary: dosage of SF > dosage of FA and BFS $>$ dosage ratio of FA/BFS. Among them, the range results of the dosage of SF are much larger than those of the dosage of FA and BFS and their dosage ratio, which shows that the dosage of SF has an absolute influence on the 


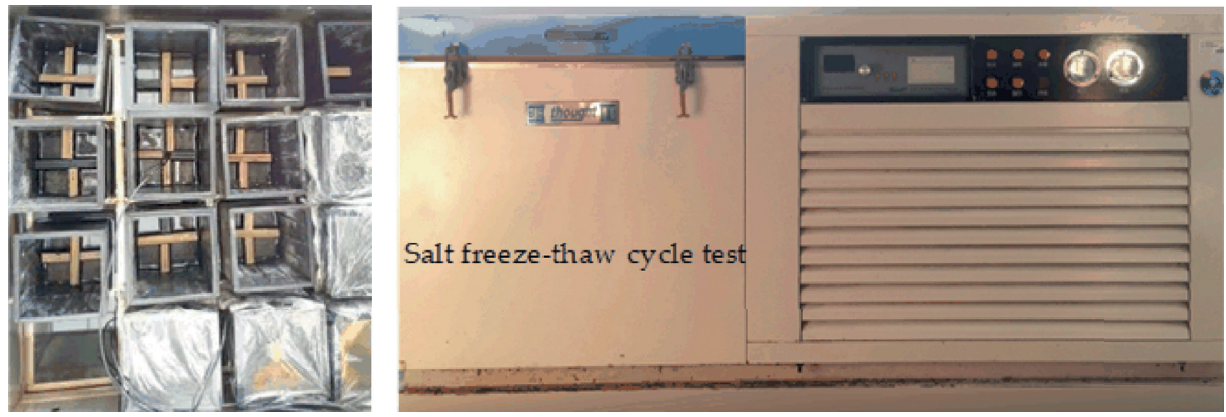

Figure 4: Salt freeze-thaw cycles test of cement concrete.

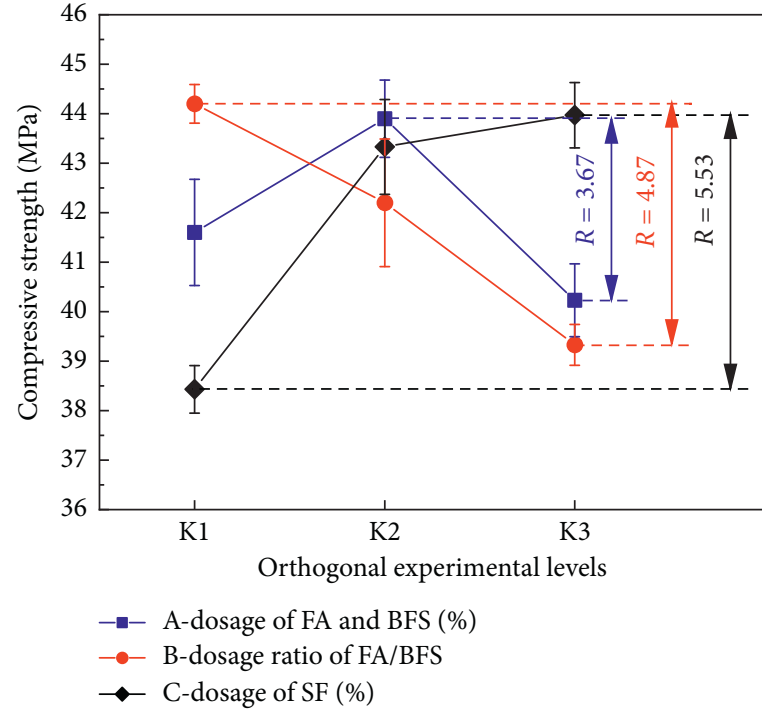

(a)

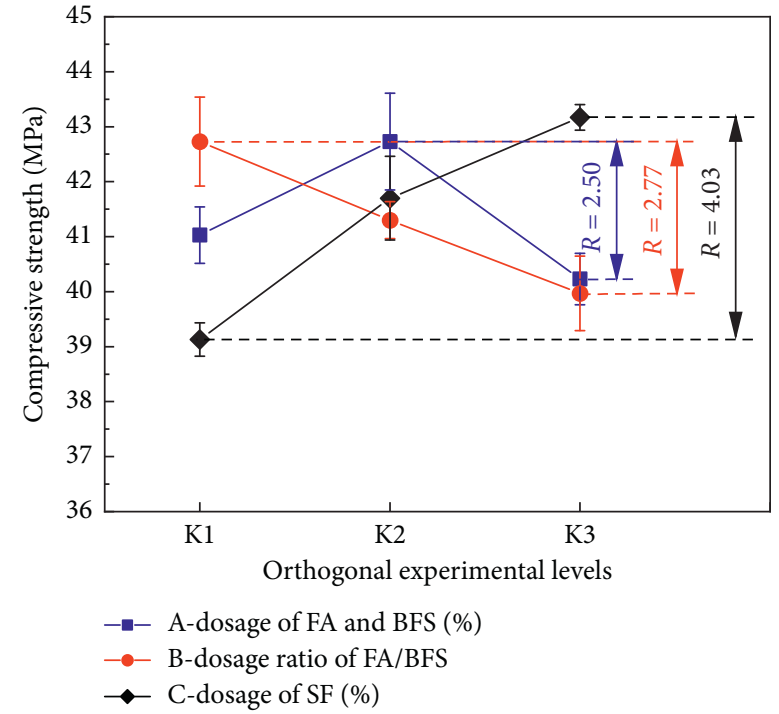

(b)

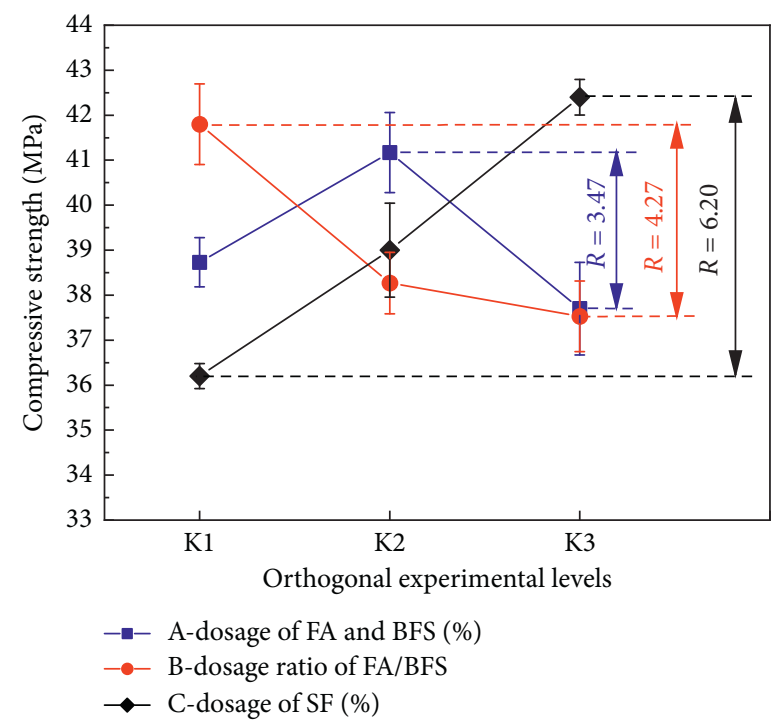

(c)

Figure 5: Range analysis between compressive strength and orthogonal experimental levels of cement concrete. (a) Air content of $(2.5 \pm 0.5) \%$. (b) Air content of $(4.5 \pm 0.5) \%$. (c) Air content of $(6.5 \pm 0.5) \%$. 


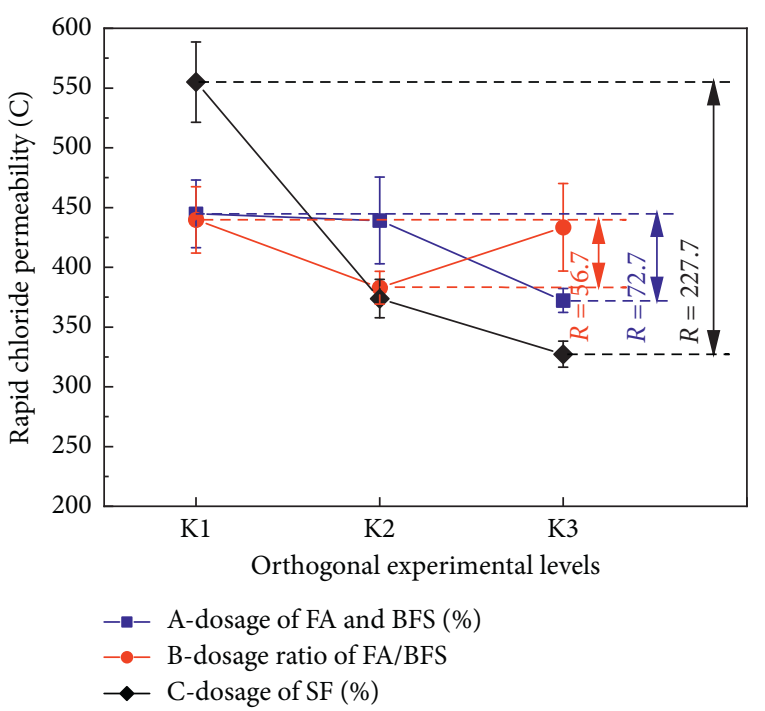

(a)

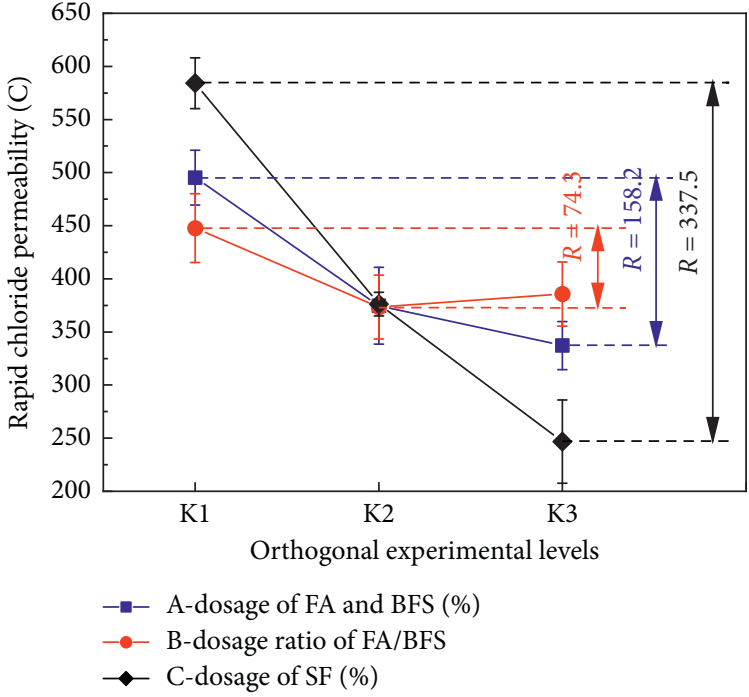

(b)

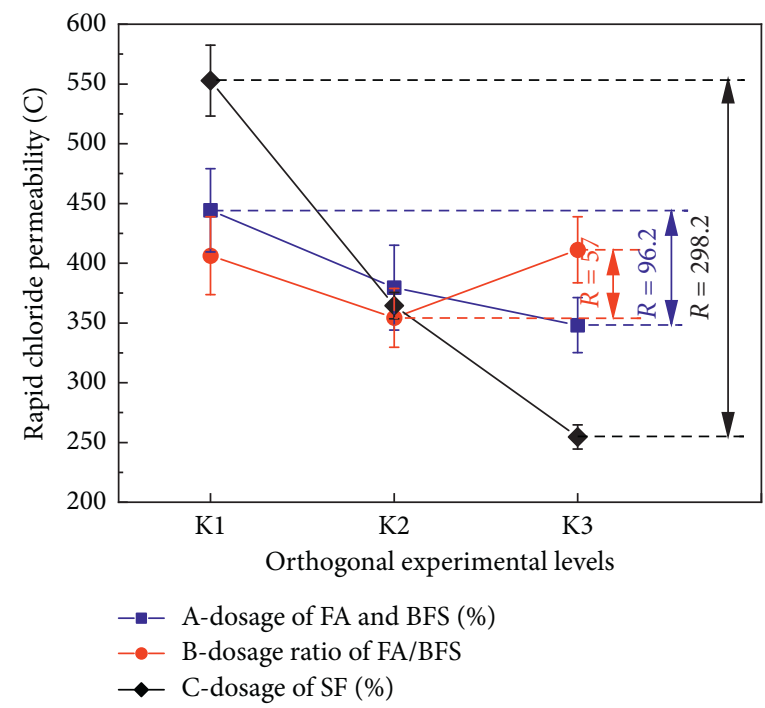

(c)

FiguRE 6: Range analysis between rapid chloride permeability and orthogonal experimental levels of cement concrete. (a) Air content of $(2.5 \pm 0.5) \%$. (b) Air content of $(4.5 \pm 0.5) \%$. (c) Air content of $(6.5 \pm 0.5) \%$.

rapid chloride permeability of concrete with triple-admixtures. Moreover, the rapid chloride permeability of concrete with triple-admixtures shows a downward trend as the dosage of SF increases. This is due to the small particle size of SF, which can change the size and number of air voids in concrete and effectively reduce the pore size. In addition, incorporating FA and BFS can also reduce the permeability of concrete, thereby improving its durability against salt and freeze-thaw cycles. Therefore, the rapid chloride permeability of concrete with triple-admixtures decreases with increase of dosage of FA and BFS as well as dosage ratio of FA/BFS. Simultaneously, comparing the rapid chloride permeability results of concrete with different air contents, it can be seen that the rapid chloride permeability of concrete with triple-admixtures decreases slightly with the increase of air contents.
3.1.3. Weight Loss after 50 Salt Freeze-Thaw Cycles. The range analysis results of weight loss after 50 salt freeze-thaw cycles of concrete with triple-admixtures are shown in Figure 7. It can be seen from Figure 7 that the factors affecting the weight loss after 50 salt freeze-thaw cycles of concrete with triple-admixtures are as follows in the order of primary and secondary: dosage of FA and BFS $>$ dosage ratio of FA/BFS > dosage of SF. Among them, the range results of the dosage of FA and BFS are much larger than those of the dosage ratio of FA/BFS and dosage of SF, which shows that the dosage of FA and BFS has more influence on the weight loss after 50 salt freeze-thaw cycles of concrete with tripleadmixtures. The weight loss after 50 salt freeze-thaw cycles of concrete with triple-admixtures shows a downward trend as the dosage of SF increases. The reason is mainly due to the small particle size of SF, which can participate in the 


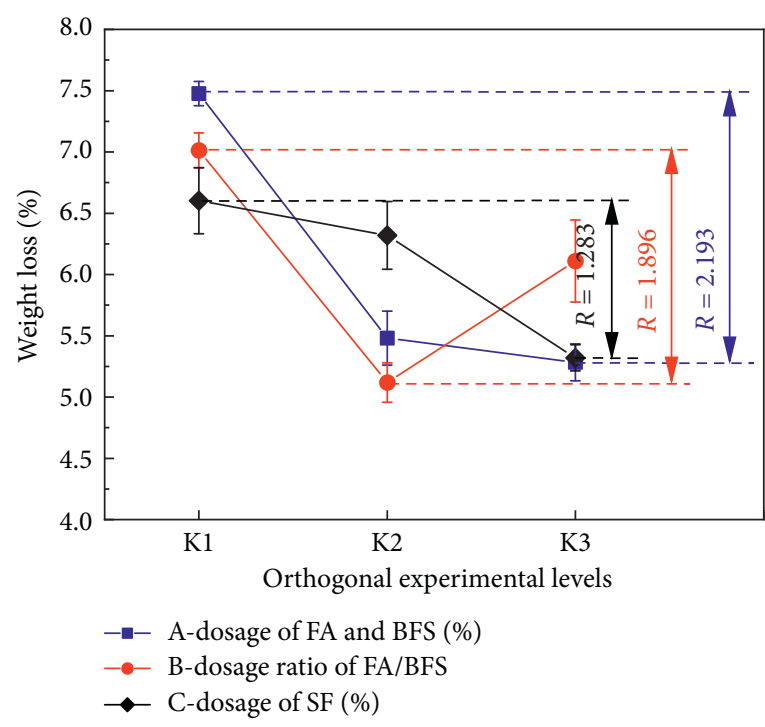

(a)

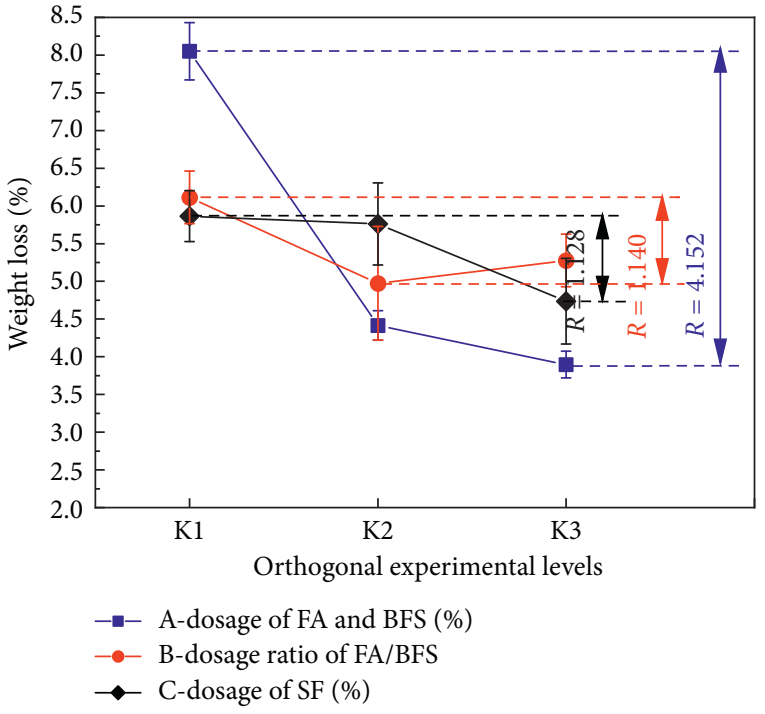

(b)

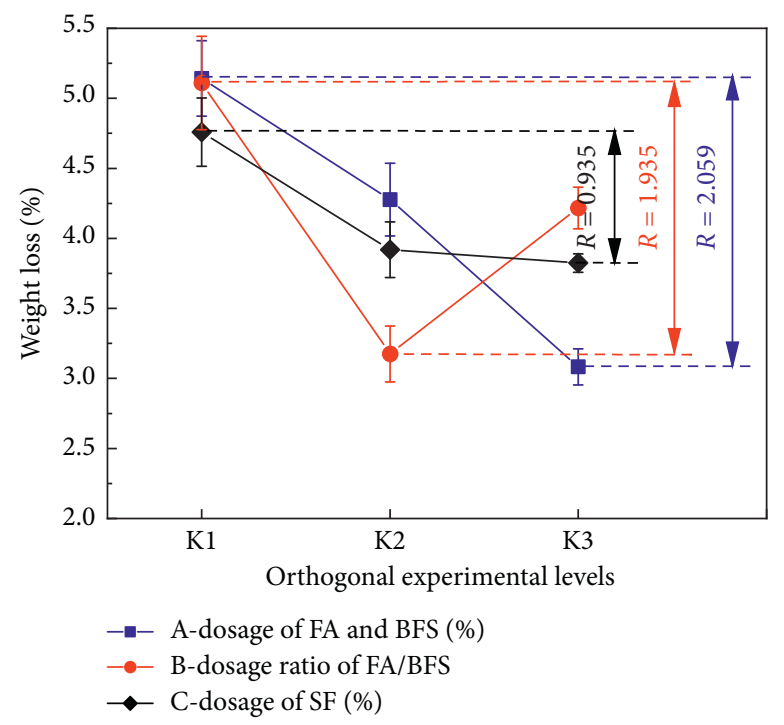

(c)

Figure 7: Range analysis between weight loss and orthogonal experimental levels of cement concrete. (a) Air content of (2.5 \pm 0.5$) \%$. (b) Air content of $(4.5 \pm 0.5) \%$. (c) Air content of $(6.5 \pm 0.5) \%$.

hydration reaction of cement to produce a hard and strong cementing substance, which improves the density of concrete and improves its resistance to chloride ion penetration. Moreover, the weight loss after 50 salt freeze-thaw cycles of concrete with triple-admixtures also decreases as the dosage of FA and BFS increases. However, as the dosage ratio of FA/ BFS increases, the weight loss after 50 salt freeze-thaw cycles of concrete with triple-admixtures first decreases and then increases. The active $\mathrm{SiO}_{2}$ in the FA will react with the cement hydration product $\mathrm{CH}$ to form $\mathrm{C}-\mathrm{S}-\mathrm{H}$ gel to fill the pores of the interface layer between the aggregate and the cement paste and improve its durability. Overall, comparing the weight loss after 50 salt freeze-thaw cycles of concrete with different air contents, it can be seen that the weight loss of concrete with triple-admixtures decreases slightly with the increase of air contents.
3.1.4. Relative Dynamic Elasticity Modulus after 50 Salt Freeze-Thaw Cycles. The range analysis results of relative dynamic elasticity modulus after 50 salt freeze-thaw cycles of concrete with triple-admixtures are shown in Figure 8. It can be seen from Figure 8 that the factors affecting the weight loss after 50 salt freeze-thaw cycles of concrete with triple-admixtures are as follows in the order of primary and secondary: dosage of FA and BFS > dosage ratio of $\mathrm{FA} / \mathrm{BFS}>$ dosage of SF. Among them, the range results of the dosage of FA and BFS are much larger than those of the dosage ratio of FA/BFS and dosage of SF, which shows that the dosage of FA and BFS has more influence on the relative dynamic elasticity modulus after 50 salt freezethaw cycles of concrete with triple-admixtures. The relative dynamic elasticity modulus after 50 salt freeze-thaw cycles of concrete with triple-admixtures shows a 

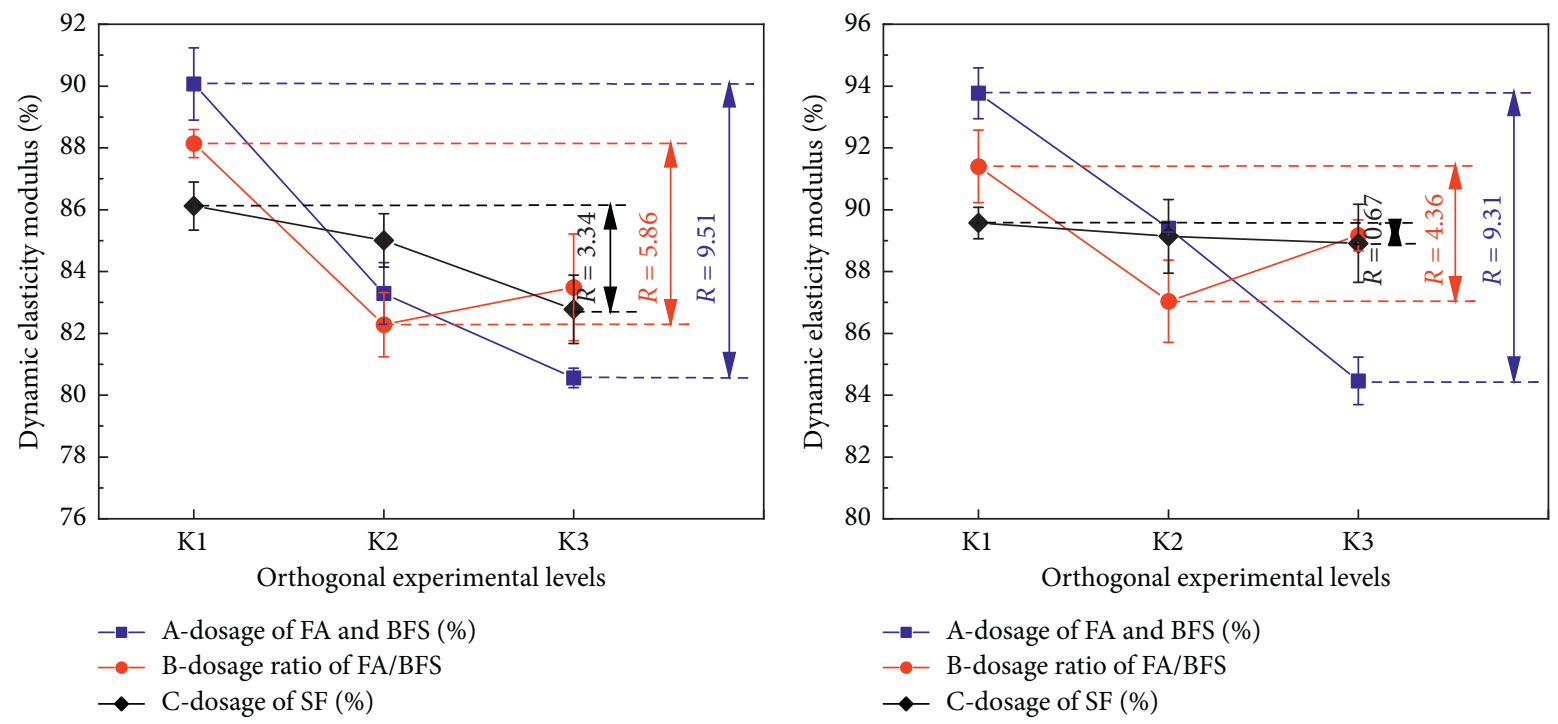

(a)

(b)

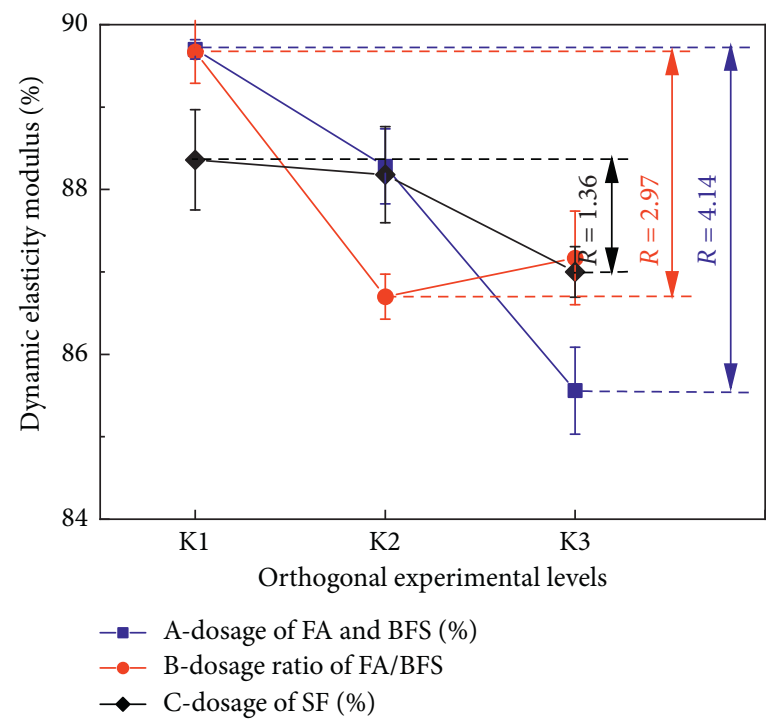

(c)

Figure 8: Range analysis between relative dynamic elasticity modulus and orthogonal experimental levels of cement concrete. (a) Air content of $(2.5 \pm 0.5) \%$. (b) Air content of $(4.5 \pm 0.5) \%$. (c) Air content of $(6.5 \pm 0.5) \%$.

downward trend as the dosage of SF as well as FA and BFS increases. However, as the dosage ratio of FA/BFS increases, the weight loss after 50 salt freeze-thaw cycles of concrete with triple-admixtures first decreases and then increases. The reinforcing effect of the secondary hydration reaction of active $\mathrm{SiO}_{2}$ in the FA with cement is greater than the reinforcing effect of BFS and SF on concrete. Meanwhile, comparing the relative dynamic elasticity modulus after 50 salt freeze-thaw cycles of concrete with different air contents, it can be seen that the relative dynamic elasticity modulus of concrete with triple-admixtures decreases slightly with the increase of air contents.

\subsection{Influence Analysis of Salt Freeze-Thaw Cycles on Durability of Concrete}

3.2.1. Weight Loss versus Salt Freeze-Thaw Cycles. During the salt freeze-thaw test in this study, the index of weight loss rate most directly reflected the process of the gradual surface erosion of concrete specimens subjected to freeze-thaw cycles in salt solution. The test results of weight loss at each air content range level varying with the number of salt freeze-thaw cycles are demonstrated in Figure 9.

In Figures 9(a)-9(c), the weight loss of concrete with triple-admixtures increases with the number of salt freeze-thaw cycles. Generally, in the conventional freeze- 


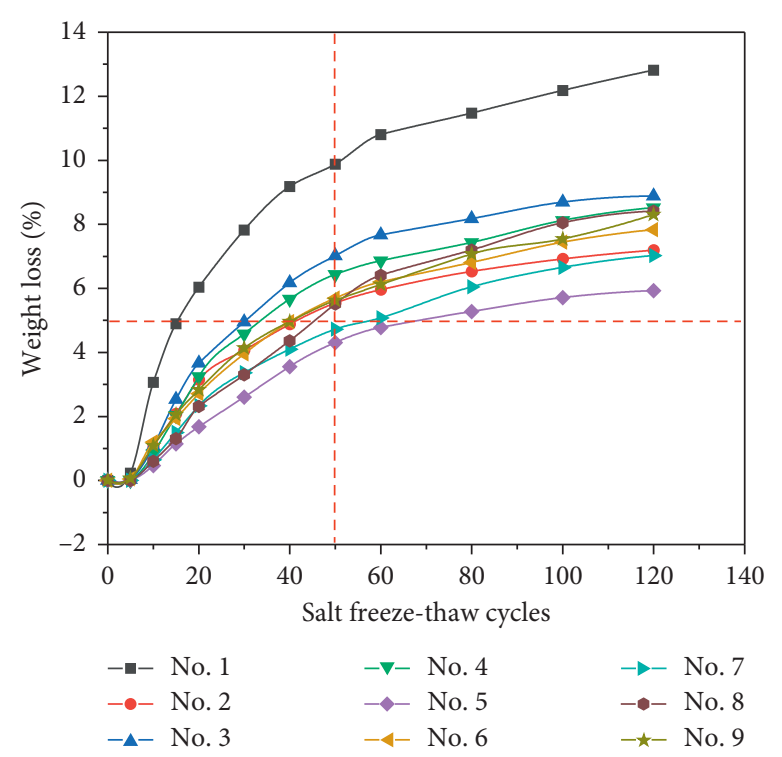

(a)

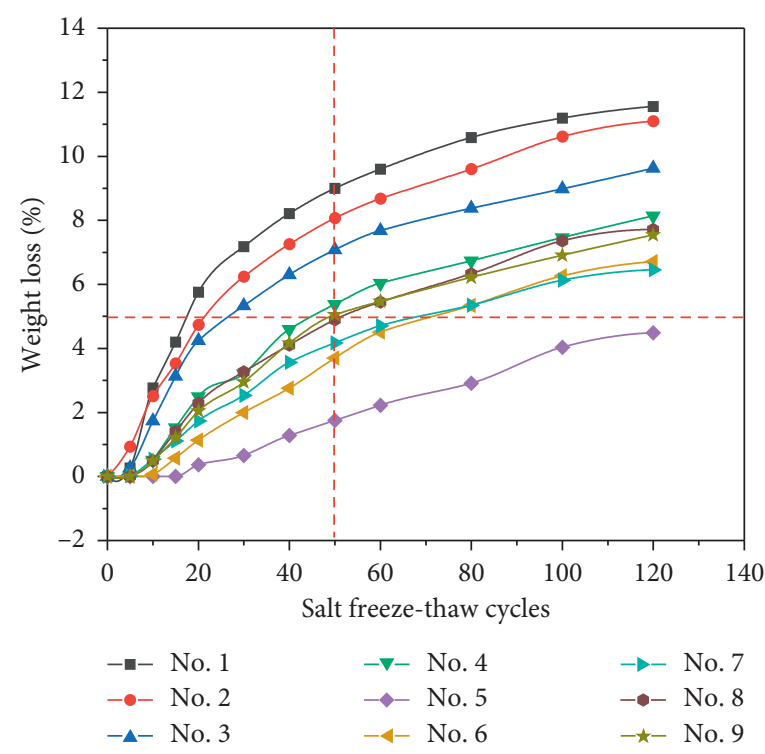

(b)

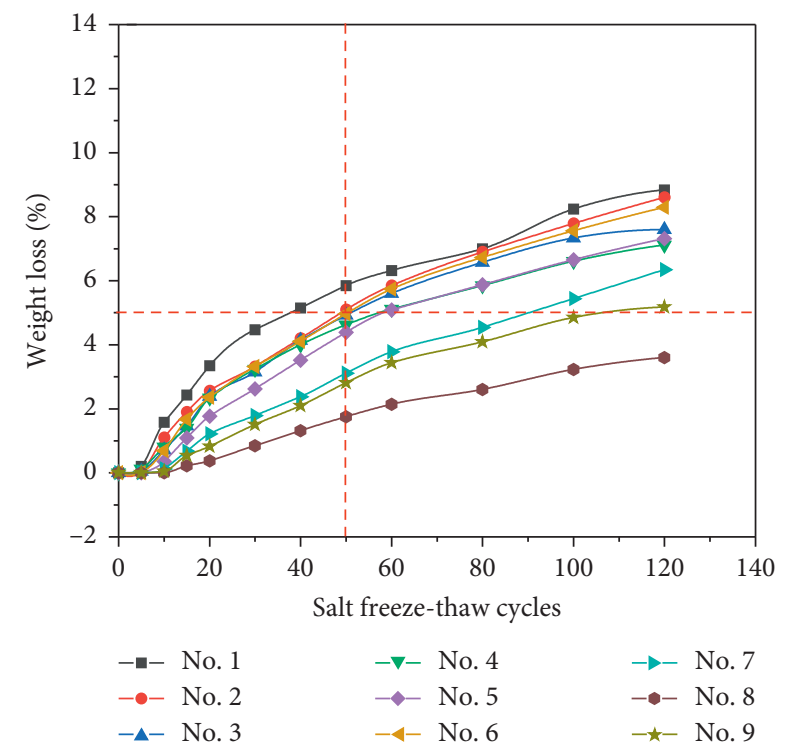

(c)

Figure 9: Weight loss of concrete with triple-admixtures versus salt freeze-thaw cycles. (a) Air content of (2.5 \pm 0.5$) \%$. (b) Air content of $(4.5 \pm 0.5) \%$. (c) Air content of $(6.5 \pm 0.5) \%$.

thaw cycle of concrete, the value $5 \%$ of weight loss is used as the evaluation index of concrete frost resistance. By comparing the 9 groups of weight loss results designed by orthogonal experiments, it can be seen that the weight loss increases with the increase in the number of salt freezethaw cycles. The addition of mineral admixtures can reduce the weight loss of concrete during the salt freezethaw process to a certain extent, which is beneficial to improve the resistance to salt freeze-thaw cycles of concrete. At the same time, the changes in the weight loss of concrete with different dosages of mineral admixtures are consistent with the range analysis results in Section 3.1.3. In addition, by comparing the weight loss of concrete with different air contents, it is obvious that the weight loss decreases with the increase of air content. This shows that adding AEA to increase air content can improve the salt freeze-thaw resistance of concrete.

3.2.2. Relative Dynamic Elasticity Modulus versus Salt Freeze-Thaw Cycles. On the other hand, the relative dynamic modulus of elasticity can also characterize the performance changes in concrete during the salt freezethaw cycles. The test results of relative dynamic modulus of elasticity at each air content range level varying with the number of salt freeze-thaw cycles are demonstrated in Figure 10. In Figures 10(a)-10(c), the relative dynamic modulus of elasticity of concrete with triple-admixtures 


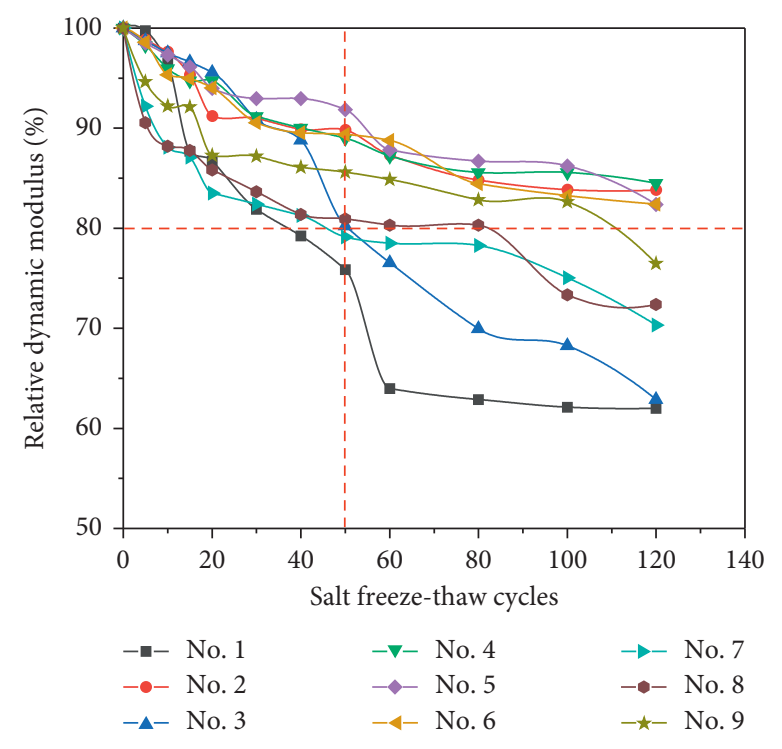

(a)

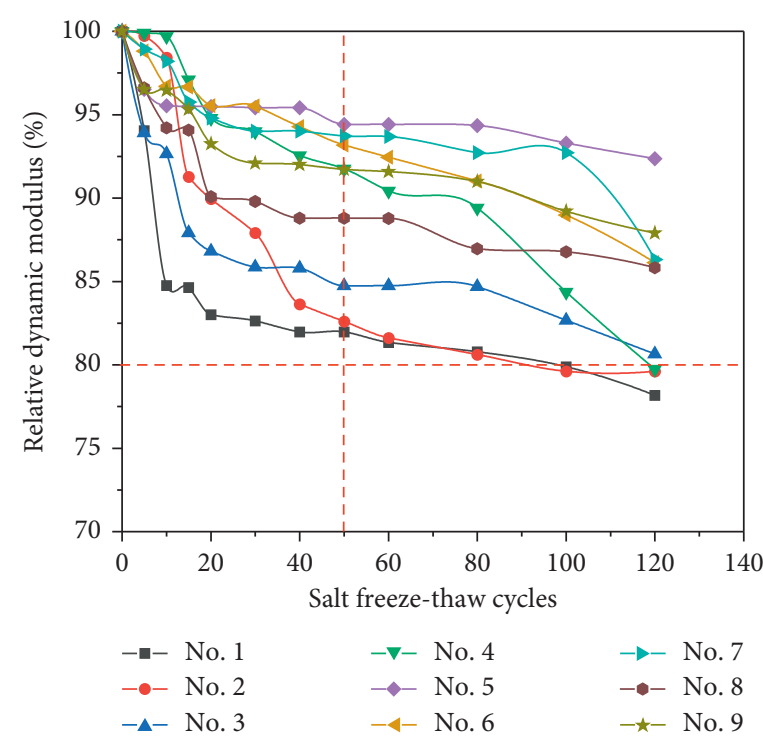

(b)

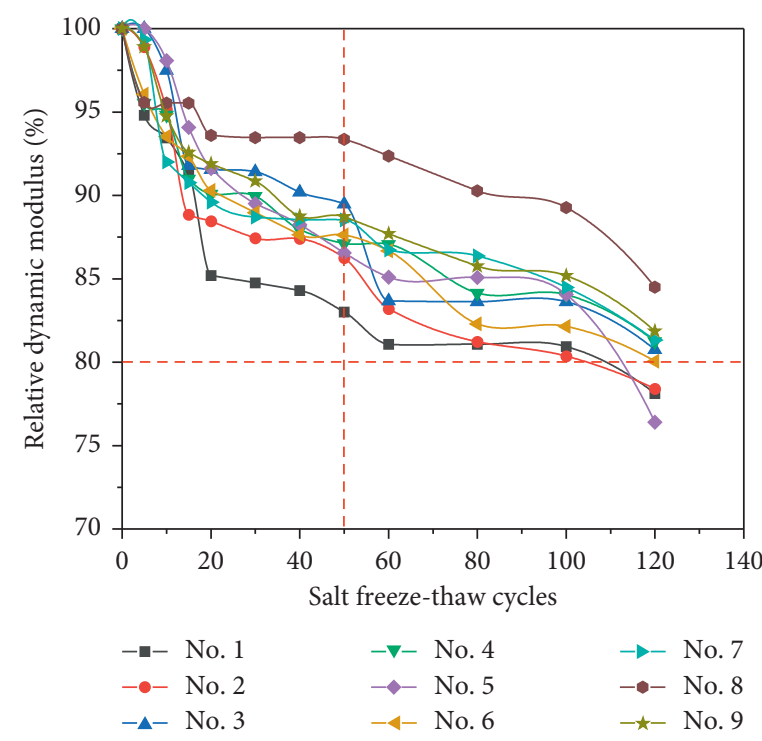

(c)

Figure 10: Relative dynamic modulus of concrete with triple-admixtures versus salt freeze-thaw cycles. (a) Air content of (2.5 \pm 0.5$) \%$. (b) Air content of $(4.5 \pm 0.5) \%$. (c) Air content of $(6.5 \pm 0.5) \%$.

decreases with the number of salt freeze-thaw cycles. The value $80 \%$ of relative dynamic modulus of elasticity is used as the evaluation index of concrete frost resistance. By comparing the 9 groups of relative dynamic modulus results designed by orthogonal experiments, it can be seen that the relative dynamic modulus decreases with the increase in the number of salt freeze-thaw cycles. Meanwhile, the addition of mineral admixtures can reduce the variation of relative dynamic modulus of concrete during the salt freeze-thaw process to a certain extent, which is also beneficial to improve the resistance to salt freeze-thaw cycles of concrete. Besides, the changes in the relative dynamic modulus of concrete with different dosages of mineral admixtures are consistent with the range analysis results in Section 3.1.3 and the change law in Section 3.2.1. Apart from this, by comparing the relative dynamic modulus of concrete with different air contents, it is obvious that the relative dynamic modulus increases with the increase of air content. This shows that adding AEA can improve the salt freeze-thaw resistance of concrete.

3.3. Mixture Proportion Optimization Based on Genetic Algorithm. In order to reflect the relationship between durability and mix proportion of concrete, the variance test fitting equation results are shown in Tables 5-7, which characterize the weight loss of concrete specimens after 120 salt freeze-thaw cycles. And the fitting results have been proved to be effective through significance test. 
TABLE 5: Fitted quadratic equations of weight loss after 120 salt freeze-thaw cycles at air content of $(2.5 \pm 0.5) \%$.

\begin{tabular}{|c|c|c|c|c|c|}
\hline Group no. & Degree of freedom & Estimated value & $F$-value & $p$-value & Significant \\
\hline A & 1 & -43.44 & 34.77 & $<0.0001$ & Yes \\
\hline B & 1 & -0.69 & 3.08 & 0.0065 & Yes \\
\hline $\mathrm{C}$ & 1 & -63.46 & 7.20 & $<0.0001$ & Yes \\
\hline$A^{2}$ & 1 & 51.62 & 16.2 & $<0.0001$ & Yes \\
\hline $\mathrm{B}^{2}$ & 1 & -0.59 & 9.23 & $<0.0001$ & Yes \\
\hline$A \times B$ & 1 & 11.15 & 40.9 & $<0.0001$ & Yes \\
\hline $\mathrm{A} \times \mathrm{C}$ & 1 & 167.23 & 7.48 & $<0.0001$ & Yes \\
\hline $\mathrm{B} \times \mathrm{C}$ & 1 & 18.93 & 9.65 & $<0.0001$ & Yes \\
\hline Intercept & 1 & 14.30 & 439.1 & $<0.0001$ & Yes \\
\hline
\end{tabular}

TABLE 6: Fitted quadratic equations of weight loss after 120 salt freeze-thaw cycles at air content of $(4.5 \pm 0.5) \%$.

\begin{tabular}{|c|c|c|c|c|c|}
\hline Group no. & Degree of freedom & Estimated value & $F$-value & $p$-value & Significant \\
\hline A & 1 & -1.25 & 1.01 & 0.3271 & No \\
\hline B & 1 & 0.52 & 2.31 & 0.0330 & Yes \\
\hline $\mathrm{C}$ & 1 & -216.31 & 24.52 & $<0.0001$ & Yes \\
\hline$A^{2}$ & 1 & -14.23 & 4.47 & 0.0003 & Yes \\
\hline $\mathrm{B}^{2}$ & 1 & -0.54 & 8.44 & $<0.0001$ & Yes \\
\hline $\mathrm{A} \times \mathrm{B}$ & 1 & -4.09 & 15.03 & $<0.0001$ & Yes \\
\hline $\mathrm{A} \times \mathrm{C}$ & 1 & 566.20 & 25.31 & $<0.0001$ & Yes \\
\hline $\mathrm{B} \times \mathrm{C}$ & 1 & 55.85 & 28.46 & $<0.0001$ & Yes \\
\hline Intercept & 1 & 12.16 & 450.12 & $<0.0001$ & Yes \\
\hline
\end{tabular}

TABLE 7: Fitted quadratic equations of weight loss after 120 salt freeze-thaw cycles at air content of $(6.5 \pm 0.5) \%$.

\begin{tabular}{|c|c|c|c|c|c|}
\hline Group no. & Degree of freedom & Estimated value & $F$-value & $p$-value & Significant \\
\hline A & 1 & 0.81 & 0.65 & 0.5258 & No \\
\hline B & 1 & 5.22 & 23.35 & $<0.0001$ & Yes \\
\hline $\mathrm{C}$ & 1 & -17.56 & 1.99 & 0.0618 & No \\
\hline $\mathrm{A}^{2}$ & 1 & -3.78 & 1.19 & 0.2505 & No \\
\hline $\mathrm{B}^{2}$ & 1 & -0.89 & 13.74 & $<0.0001$ & Yes \\
\hline $\mathrm{A} \times \mathrm{B}$ & 1 & -2.32 & 8.54 & $<0.0001$ & Yes \\
\hline $\mathrm{A} \times \mathrm{C}$ & 1 & 174.15 & 7.79 & $<0.0001$ & Yes \\
\hline $\mathrm{B} \times \mathrm{C}$ & 1 & -9.01 & 4.59 & 0.0002 & Yes \\
\hline Intercept & 1 & 2.84 & 487.87 & $<0.0001$ & Yes \\
\hline
\end{tabular}

The genetic optimization was applied to find the optimum mix proportion in this section based on the effective quadratic equations of test results on concrete with different mix proportions. Considering that the purpose of this paper is to improve the resistance to salt frost erosion, quadratic equations of weight loss in Tables 5-7 were chosen as the fitness functions of genetic algorithm. In this paper, it is a simple genetic algorithm optimization problem with the input variables "A," "B," and "C" and output variable "weight loss." The population size was regulated as 1000 , mutation rate was 0.001 , recombination rate was 0.5 , and the number of generations was 300. The experimental simulation results at each air content range level are given in Figure 11.

As it can be seen from the above results, the weight loss values tend to be stable with the increasing of generation number. And the optimum variables obtained from the genetic algorithms are listed in Table 8.
To verify the usefulness of the genetic algorithm programs, the optimum variables in Table 8 were substituted into the fitted quadratic equations; the corresponding values of compressive strength and rapid chloride permeability at each air content range level could be obtained, respectively. The results and mix proportions are shown in Table 9.

It is observed that higher air content would contribute to the reduction of weight loss. However, when the air content is raised up to $(6.5 \pm 0.5) \%$, the compressive strength of concrete decreases significantly. The optimum mix proportion of concrete with air content of $6 \%-7 \%$ has the minimum dosage of mineral admixtures, and it shows the rapid chloride permeability about three times that of other groups, which means a lower chloride ion penetration resistance. Therefore, the final recommended optimum mix proportion of concrete with multimineral admixtures in this paper is that the dosage of FA is $5.06 \%$, dosage of BFS is $6.75 \%$, dosage of SF is $7.77 \%$, and the air content should be controlled at the range of $(4.5 \pm 0.5) \%$. 


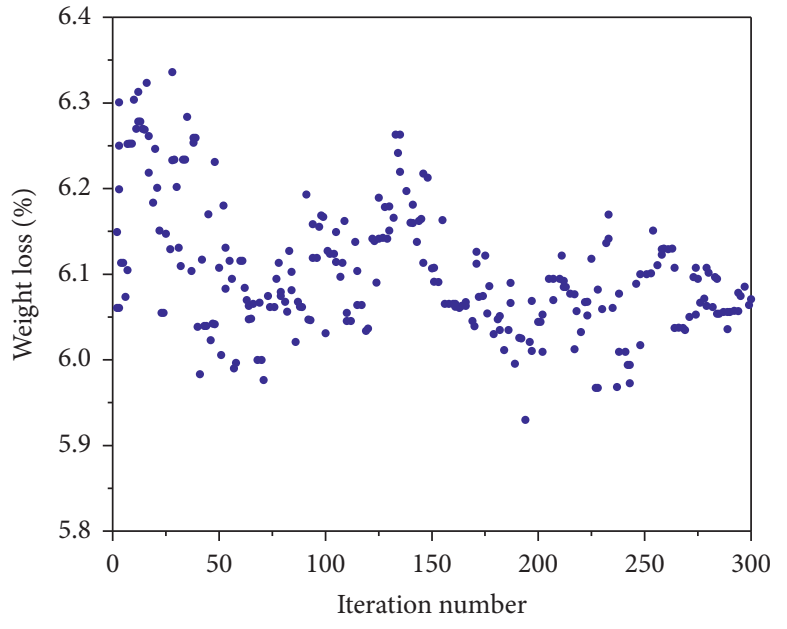

(a)

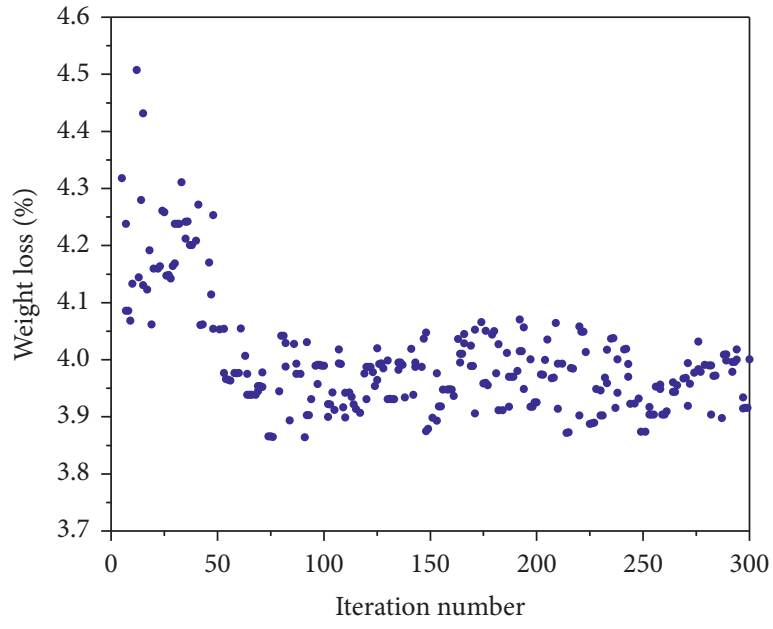

(b)

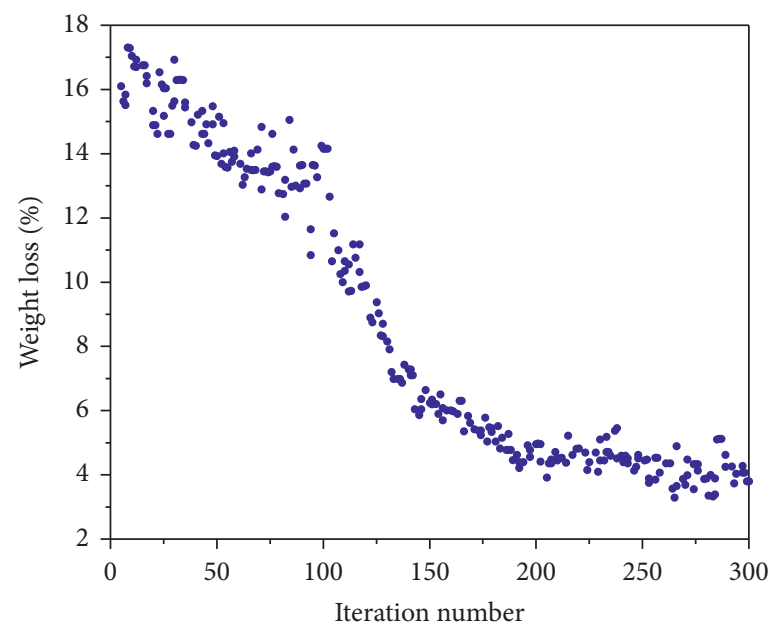

(c)

FIgURE 11: Relative dynamic modulus of concrete with triple-admixtures versus salt freeze-thaw cycles. (a) Air content of (2.5 \pm 0.5$) \%$. (b) Air content of $(4.5 \pm 0.5) \%$. (c) Air content of $(6.5 \pm 0.5) \%$.

TABLE 8: The optimum variables obtained from the genetic algorithms.

\begin{tabular}{cccccc}
\hline Air content & Iteration number & A & B & C & Weight loss (\%) \\
\hline$(2.5 \pm 0.5) \%$ & 178 & 24.2 & 0.343 & 8.8 & 5.92 \\
$(4.5 \pm 0.5) \%$ & 248 & 11.8 & 0.748 & 7.8 & 3.86 \\
$(6.5 \pm 0.5) \%$ & 283 & 10.3 & 0.338 & 3.3 & 3.28 \\
\hline
\end{tabular}

TABLE 9: The optimum mix proportions and predicted values of concrete under salt freeze-thaw cycles.

\begin{tabular}{|c|c|c|c|c|c|c|}
\hline Air content & Compressive strength (MPa) & Chloride permeability (C) & Weight loss (\%) & FA (\%) & BFS (\%) & SF $(\%)$ \\
\hline$(2.5 \pm 0.5) \%$ & 51.94 & 202.36 & 5.97 & 6.19 & 18.02 & 8.84 \\
\hline$(4.5 \pm 0.5) \%$ & 49.17 & 234.37 & 3.32 & 5.06 & 6.75 & 7.77 \\
\hline$(6.5 \pm 0.5) \%$ & 37.44 & 631.77 & 4.92 & 2.60 & 7.70 & 3.04 \\
\hline
\end{tabular}

\section{Conclusions}

The object of this research is to propose a mix proportion design method for air-entrained concrete with multiadmixtures, which would improve the durability of concrete serving in salt freeze-thaw condition. Firstly, the orthogonal experiment about different dosages of three kinds of mineral admixtures was designed to reduce the number of trial mixes and three range levels of air content were taken into consideration simultaneously. Then, the salt freeze-thaw resistance 
indices of concrete such as compressive strength, rapid chloride permeability, weight loss, and relative dynamic modulus of elasticity were tested. Finally, the test results were fitted into quadratic equations and an ordinary genetic algorithm was applied to optimize the mix proportion. Based on the results of this research, the following conclusions are reached.

(1) In order to evaluate the salt freeze-thaw resistance of concrete, indices such as compressive strength, rapid chloride permeability, weight loss, and relative dynamic modulus of elasticity should be considered at the same time, which reflect the basic strength, chloride ion penetration resistance, surface erosion resistance, and internal defects resistance of concrete suffering from freeze-thaw environment.

(2) Combined with engineering experience and correlative study, applying orthogonal design would reduce the number of trial mixes significantly. Quadratic fitting and genetic algorithm are both practical methods to analyze and optimize data for the problem discussed in this paper. The method proposed by the authors will considerably improve the quantity and efficiency of mix proportion design for this kind of multiconstituent concrete.

(3) It may cause obvious difference in salt freeze-thaw resistance of concrete when changing the proportions of mineral admixtures and air content. An appropriate amount of mineral admixtures would improve pore structures and chloride ion penetration resistance of concrete, while overmuch mineral admixtures, especially FA, would bring negative impact on strength and surface erosion resistance. On the other hand, the addition of AEA could prominently improve salt freeze-thaw durability of concrete, while overmuch air content will cause obvious decrease in concrete strength.

(4) Finally, the recommended optimum mix proportion of air-entrained concrete with multimineral admixtures in this paper is that the dosage of FA is $5.06 \%$, dosage of $\mathrm{BFS}$ is $6.75 \%$, dosage of SF is $7.77 \%$, and the air content should be controlled at the range of $(4 \pm 0.5) \%$.

This study only evaluated the macroscopic durability behaviour of concrete with triple-admixtures subjected to freeze-thaw cycles in salt solution and did not conduct indepth analysis from the aspect of microscopic mechanism, which is also the future direction of this research work.

\section{Data Availability}

The data used to support the findings of this study are available from the corresponding author upon request.

\section{Conflicts of Interest}

The authors declare that they have no conflicts of interest.

\section{Acknowledgments}

This work was partially financially supported by the Scientific and Technological Project of Science and Technology Department of Jilin Province (grant number 20190303052SF) and the Innovation Special Project of Zhongshan Science and Technology Bureau (grant number 2019AG001).

\section{References}

[1] Y. B. Jiao, Y. Zhang, M. Guo, L. Zhang, H. Ning, and S. Liu, "Mechanical and fracture properties of ultra-high performance concrete (uhpc) containing waste glass sand as partial replacement material," Journal of Cleaner Production, vol. 277, Article ID 123501, 2020.

[2] C. S. Poon, S. C. Kou, and L. Lam, "Compressive strength, chloride diffusivity and pore structure of high performance metakaolin and silica fume concrete," Construction and Building Materials, vol. 20, no. 10, pp. 858-865, 2006.

[3] F. Pacheco-Torgal, Y. N. Ding, and S. Jalali, "Properties and durability of concrete containing polymeric wastes (tyre rubber and polyethylene terephthalate bottles): an overview," Construction and Building Materials, vol. 30, pp. 714-724, 2012.

[4] H. B. Liu, G. B. Luo, H. B. Wei, and H. Yu, "Strength, permeability, and freeze-thaw durability of pervious concrete with different aggregate sizes, porosities, and water-binder ratios," Applied Sciences-Basel, vol. 8, no. 8, p. 1217, 2018.

[5] G. Tan, Z. Zhu, W. Wang et al., "Flexural ductility and crackcontrolling capacity of polypropylene fiber reinforced ecc thin sheet with waste superfine river sand based on acoustic emission analysis," Construction and Building Materials, vol. 277, Article ID 122321, 2021.

[6] X. J. Shi, P. Park, Y. Rew, K. Huang, and C. Sim, "Constitutive behaviors of steel fiber reinforced concrete under uniaxial compression and tension," Construction and Building Materials, vol. 233, 2020.

[7] W. S. Wang, Y. C. Cheng, and G. J. Tan, "Design optimization of sbs-modified asphalt mixture reinforced with eco-friendly basalt fiber based on response surface methodology," Materials, vol. 11, no. 8, p. 1131, 2018.

[8] K. Amini, P. Vosoughi, H. Ceylan, and P. Taylor, "Effect of mixture proportions on concrete performance," Construction and Building Materials, vol. 212, pp. 77-84, 2019.

[9] H. B. Liu, S. Q. Liu, P. L. Zhou, Y. Zhang, Y. Jiao et al., "Mechanical properties and crack classification of basalt fiber rpc based on acoustic emission parameters," Applied SciencesBasel, vol. 9, no. 18, 2019.

[10] W. J. Long, K. H. Khayat, A. Yahia, and F. Xiang, "Rheological approach in proportioning and evaluating prestressed selfconsolidating concrete," Cement \& Concrete Composites, vol. 82, pp. 105-116, 2017.

[11] X. J. Shi, A. Mukhopadhyay, D. Zollinger, and Z. Grasley, "Economic input-output life cycle assessment of concrete pavement containing recycled concrete aggregate," Journal of Cleaner Production, vol. 225, pp. 414-425, 2019.

[12] X. J. Shi, A. Mukhopadhyay, and K. W. Liu, "Mix design formulation and evaluation of portland cement concrete paving mixtures containing reclaimed asphalt pavement," Construction and Building Materials, vol. 152, pp. 756-768, 2017. 
[13] H. J. Wu, Z. Diao, and K. Z. Fan, "Study on durability of nondispersible concrete in seawater environment," International Journal of Structural Integrity, vol. 11, no. 3, pp. 443-452, 2020.

[14] N. Xie, M. Akin, and X. M. Shi, "Permeable concrete pavements: a review of environmental benefits and durability," Journal of Cleaner Production, vol. 210, pp. 1605-1621, 2019.

[15] G. Dimitriou, P. Savva, and M. F. Petrou, "Enhancing mechanical and durability properties of recycled aggregate concrete," Construction and Building Materials, vol. 158, pp. 228-235, 2018.

[16] H. B. Liu, G. B. Luo, Y. F. Gong, H. Wei et al., "Mechanical properties, permeability, and freeze-thaw resistance of pervious concrete modified by waste crumb rubbers," Applied Sciences-Basel, vol. 8, no. 10, 2018.

[17] W. S. Wang, G. J. Tan, C. Y. Liang, Y. Wang, and Y. Cheng, "Study on viscoelastic properties of asphalt mixtures incorporating sbs polymer and basalt fiber under freeze-thaw cycles," Polymers, vol. 12, no. 8, 2020.

[18] N. Xie, X. M. Shi, and Y. Zhang, "Impacts of potassium acetate and sodium-chloride deicers on concrete," Journal of Materials in Civil Engineering, vol. 29, no. 3, 2017.

[19] Y. Farnam, M. Krafcik, L. Liston et al., "Evaluating the use of phase change materials in concrete pavement to melt ice and snow," Journal of Materials in Civil Engineering, vol. 28, no. 4, 2016.

[20] Z. H. Sun and G. W. Scherer, "Measurement and simulation of dendritic growth of ice in cement paste," Cement and Concrete Research, vol. 40, no. 9, pp. 1393-1402, 2010.

[21] J. Yuan, H. Lu, Q. B. Yang, and J. Ling, "Mechanisms on the salt-frost scaling of concrete," Journal of Materials in Civil Engineering, vol. 29, no. 3, 2017.

[22] B. Lei, W. G. Li, Z. Tang, V. W. Y. Tam, and Z. Sun, "Durability of recycled aggregate concrete under coupling mechanical loading and freeze-thaw cycle in salt-solution," Construction and Building Materials, vol. 163, pp. 840-849, 2018.

[23] Q. L. Guo, Q. Liu, P. Zhang et al., "Temperature and pressure dependent behaviors of moisture diffusion in dense asphalt mixture," Construction and Building Materials, vol. 246, 2020.

[24] Q. L. Guo, G. Y. Li, Y. Gao et al., "Experimental investigation on bonding property of asphalt-aggregate interface under the actions of salt immersion and freeze-thaw cycles," Construction and Building Materials, vol. 206, pp. 590-599, 2019.

[25] G. J. Ke, J. Zhang, B. Tian, and J. Wang, "Characteristic analysis of concrete air entraining agents in different media," Cement and Concrete Research, vol. 135, 2020.

[26] F. L. Huang, H. J. Li, Z. L. Yi, Z. Wang, and Y. Xie, "The rheological properties of self-compacting concrete containing superplasticizer and air-entraining agent," Construction and Building Materials, vol. 166, pp. 833-838, 2018.

[27] D. M. Wellman, K. E. Parker, L. Powers et al., "Effect of iron and carbonation on the diffusion of iodine and rhenium in waste encasement concrete and soil fill material under hydraulically unsaturated conditions," Applied Geochemistry, vol. 23, no. 8, pp. 2256-2271, 2008.

[28] G. C. Shan, S. Zhao, M. Qiao et al., "Synergism effects of coconut diethanol amide and anionic surfactants for entraining stable air bubbles into concrete," Construction and Building Materials, vol. 237, 2020.

[29] M. Khoshroo, A. A. S. Javid, and A. Katebi, "Effect of chloride treatment curing condition on the mechanical properties and durability of concrete containing zeolite and micro-nano- bubble water," Construction and Building Materials, vol. 177, pp. 417-427, 2018.

[30] L. X. Du and K. J. Folliard, "Mechanisms of air entrainment in concrete," Cement and Concrete Research, vol. 35, no. 8, pp. 1463-1471, 2005.

[31] S. Chatterji, "Freezing of air-entrained cement-based materials and specific actions of air-entraining agents," Cement \& Concrete Composites, vol. 25, no. 7, pp. 759-765, 2003.

[32] Z. C. Liu and W. Hansen, "Pore damage in cementitious binders caused by deicer salt frost exposure," Construction and Building Materials, vol. 98, pp. 204-216, 2015.

[33] J. Yuan, Z. Y. Du, Y. Wu, and F. P Xiao, "Freezing-thawing resistance evaluations of concrete pavements with deicing salts based on various surfaces and air void parameters," Construction and Building Materials, vol. 204, pp. 317-326, 2019.

[34] P. Duan, Z. H. Shui, W. Chen, and C. Shen, "Efficiency of mineral admixtures in concrete: microstructure, compressive strength and stability of hydrate phases," Applied Clay Science, vol. 83-84, pp. 115-121, 2013.

[35] H. B. Liu, G. B. Luo, L. H. Wang, and Y. F. Gong, "Strength time-varying and freeze-thaw durability of sustainable pervious concrete pavement material containing waste fly ash," Sustainability, vol. 11, no. 1, p. 176, 2019.

[36] J. J. Valenza and G. W. Scherer, "Mechanism for salt scaling of a cementitious surface," Materials and Structures, vol. 40, no. 3, pp. 259-268, 2007.

[37] B. Amini and S. S. Tehrani, "Simultaneous effects of salted water and water flow on asphalt concrete pavement deterioration under freeze-thaw cycles," International Journal of Pavement Engineering, vol. 15, no. 5, pp. 1-9, 2014.

[38] S. H. Han, "Influence of diffusion coefficient on chloride ion penetration of concrete structure," Construction and Building Materials, vol. 21, no. 2, pp. 370-378, 2007.

[39] Q. Yuan, D. J. Zhou, B. Y. Li, H. Huang, and C. Shi, "Effect of mineral admixtures on the structural build-up of cement paste," Construction and Building Materials, vol. 160, pp. 117-126, 2018.

[40] C. Wu, L. Li, W. Wang, and Z. W. Gu, "Experimental characterization of viscoelastic behaviors of nano-tio2/caco3 modified asphalt and asphalt mixture," Nanomaterials (Basel), vol. 11, no. 1, 2021.

[41] Y. Li, J. L. Bao, and Y. L. Guo, "The relationship between autogenous shrinkage and pore structure of cement paste with mineral admixtures," Construction and Building Materials, vol. 24, no. 10, pp. 1855-1860, 2010.

[42] W. Sun, Y. S. Zhang, S. F. Liu, and Y. M. Zhang, "The influence of mineral admixtures on resistance to corrosion of steel bars in green high-performance concrete," Cement and Concrete Research, vol. 34, no. 10, pp. 1781-1785, 2004.

[43] J. D. Bapat, "Performance of cement concrete with mineral admixtures," Advances in Cement Research, vol. 13, no. 4, pp. 139-155, 2001.

[44] C. H. Lim, Y. S. Yoon, and J. H. Kim, "Genetic algorithm in mix proportioning of high-performance concrete," Cement and Concrete Research, vol. 34, no. 3, pp. 409-420, 2004.

[45] C. Liang, X. Xu, H. Chen et al., "Machine learning approach to develop a novel multi-objective optimization method for pavement material proportion," Applied Sciences, vol. 11, no. 2, p. 835, 2021.

[46] M. Shahnewaz, R. Machial, M. S. Alam, and A. Rteil, "Optimized shear design equation for slender concrete beams reinforced with frp bars and stirrups using genetic algorithm 
and reliability analysis," Engineering Structures, vol. 107, pp. 151-165, 2016.

[47] S. Kim, H. B. Choi, Y. Shin, G. H. Kim, and D. S. Seo, "Optimizing the mixing proportion with neural networks based on genetic algorithms for recycled aggregate concrete," Advances in Materials Science and Engineering, vol. 2013, Article ID 527089, 10 pages, 2013.

[48] W. J. Park, T. Noguchi, and H. S. Lee, "Genetic algorithm in mix proportion design of recycled aggregate concrete," Computers and Concrete, vol. 11, no. 3, pp. 183-199, 2013.

[49] H. Yazici, "The effect of silica fume and high-volume class c fly ash on mechanical properties, chloride penetration and freeze-thaw resistance of self-compacting concrete," Construction and Building Materials, vol. 22, no. 4, pp. 456-462, 2008.

[50] C. W. Chung, C. S. Shon, and Y. S. Kim, "Chloride ion diffusivity of fly ash and silica fume concretes exposed to freeze-thaw cycles," Construction and Building Materials, vol. 24, no. 9, pp. 1739-1745, 2010.

[51] A. Mardani-Aghabaglou, G. I. Sezer, and K. Ramyar, "Comparison of fly ash, silica fume and metakaolin from mechanical properties and durability performance of mortar mixtures view point," Construction and Building Materials, vol. 70, pp. 17-25, 2014.

[52] H. Ziari, P. Hayati, and J. Sobhani, "Airfield self-consolidating concrete pavements (asccp): mechanical and durability properties," Construction and Building Materials, vol. 72, pp. 174-181, 2014.

[53] M. J. Islam, M. S. Meherier, and A. K. M. R. Islam, "Effects of waste pet as coarse aggregate on the fresh and harden properties of concrete," Construction and Building Materials, vol. 125, pp. 946-951, 2016.

[54] W. S. Wang, Y. C. Cheng, H. P. Chen, G. J. Tan, Z. Lv, and Y.S. Bai, "Study on the performances of waste crumb rubber modified asphalt mixture with eco-friendly diatomite and basalt fiber," Sustainability, vol. 11, no. 19, p. 5282, 2019.

[55] Q. L. Guo, L. L. Li, Y. C. Cheng, Y. Jiao, and C. Xu, "Laboratory evaluation on performance of diatomite and glass fiber compound modified asphalt mixture," Materials \& Design, vol. 66, pp. 51-59, 2015.

[56] Q. L. Guo, H. Y. Wang, Y. Gao, Y. Jiao, F. Liu, and Z. Dong, "Investigation of the low-temperature properties and cracking resistance of fiber-reinforced asphalt concrete using the dic technique," Engineering Fracture Mechanics, vol. 229, 2020.

[57] Q. Guo, Z. Chen, P. Liu et al., "Influence of basalt fiber on mode $i$ and ii fracture properties of asphalt mixture at medium and low temperatures," Theoretical and Applied Fracture Mechanics, vol. 112, 2021. 